\title{
PERFORMANCE OF A PERSONAL NEUTRON DOSEMETER BASED ON DIRECT ION STORAGE AT WORKPLACE FIELDS IN THE NUCLEAR INDUSTRY
}

\author{
M. Boschung*, A. Fiechtner and C. Wernli \\ PSI-Paul Scherrer Institute, 5232 Villigen PSI, Switzerland
}

\begin{abstract}
In the framework of the EVIDOS project, funded by the EC, measurements were carried out using dosemeters, based on ionisation chambers with direct ion storage (DIS-N), at several workplace fields, namely, at a fuel processing plant, a boiling and a pressurised water reactor, and near transport and storage casks. The measurements and results obtained with the DIS-N in these workplaces, which are representative for the nuclear industry, are described in this study. Different dosemeter configurations of converter and shielding materials were considered. The results are compared with values for personal dose equivalent which were assessed within the EVIDOS project by other partners. The advantages and limitations of the DIS-N dosemeter are discussed.
\end{abstract}

\section{DOSEMETER DESIGN AND DOSE DETERMINATION}

The personal neutron dosemeter DIS-N, developed by RADOS, is based on ionisation chambers with direct ion storage and a double-chamber system which allows for differential readings to separate the neutron from the photon dose equivalent ${ }^{(1)}$. However, ionisation chambers are sensitive to both neutrons and photons. Therefore, application of the double-chamber principle requires that the photon energy sensitivities of the two chambers are almost equal and the neutron energy sensitivities of the two chambers are significantly different.

Four different types of dosemeter were investigated within the EVIDOS project. The chamber with a high sensitivity for fast neutrons is build with tissue-equivalent wall material (A-150) or polyethylene (PE) for the detection of recoil protons. The response to thermal neutrons can be modified by adding boron nitride (BN) to A-150 or $\mathrm{LiNO}_{3}$ to $\mathrm{PE}$ and by surrounding the dosemeter with additional 'boron-covers' (containing 40\% $\mathrm{B}_{4} \mathrm{C}$ ). Thermal neutrons can then be detected by the secondary charged particles of the $(n, \alpha)$ reaction with ${ }^{10} \mathrm{~B}$ and ${ }^{6} \mathrm{Li}$, respectively, while the boron-covers will reduce the thermal neutron flux.

The chamber with a low sensitivity to neutrons was in all cases made up of Teflon (polytetraflouroethylene) containing $60 \%$ graphite. Owing to a $1-\mathrm{mm}$-thick tin shielding around the chambers, photon energies $<100 \mathrm{keV}$ may be neglected.

The following combinations of wall materials and boron-covers of the chamber with a high-neutron response to fast neutrons were used:

- PE with $4 \% \mathrm{LiNO}_{3}$.

- $\mathrm{PE}$ with $4 \% \mathrm{LiNO}_{3}$ and $1 \mathrm{~mm} \mathrm{~B} \mathrm{~B}_{4} \mathrm{C}$.

*Corresponding author: markus.boschung@psi.ch
- A-150 with $1.25 \%$ BN.

- A-150 with $1.25 \% \mathrm{BN}$ and $2 \mathrm{~mm} \mathrm{~B}_{4} \mathrm{C}$.

The measured quantities $N_{1}$ and $N_{2}$ (arbitrary units, a.u.) in both chambers 1 (high-neutron sensitivity) and 2 (low-neutron sensitivity) in a mixed neutron/ photon field are due to the sum of neutron-induced and photon-induced effects and can be written as follows:

$$
\begin{aligned}
& N_{1}=H_{\mathrm{n}} \cdot S_{1 \mathrm{n}}+H_{\gamma} \cdot S_{1 \gamma} \\
& N_{2}=H_{\mathrm{n}} \cdot S_{2 \mathrm{n}}+H_{\gamma} \cdot S_{2 \gamma}
\end{aligned}
$$

where $H_{\mathrm{n}}$ and $H_{\gamma}$ are the neutron and photon dose equivalent; $S_{1 \mathrm{n}}$ and $S_{2 \mathrm{n}}$ are the neutron sensitivities of chambers 1 and 2; and $S_{1 \gamma}$ and $S_{2 \gamma}$ are the photon sensitivities of chambers 1 and 2. The sensitivities $S_{\mathrm{i}}$ are average sensitivities dependent on the angular and energy distribution of the neutron and photon fields. The neutron dose equivalent can then be determined by

$$
H_{\mathrm{n}}=\frac{N_{1}-N_{2} \cdot k_{\gamma}}{S_{1 \mathrm{n}}-S_{2 \mathrm{n}} \cdot k_{\gamma}}
$$

where $k_{\gamma}$ is the ratio of the photon sensitivities in chambers 1 and 2. Under the condition that the sensitivities to photons in both chambers are equal, the neutron dose is the quotient of the difference in the measured quantities $\left(N_{1}-N_{2}\right)$ and the difference of neutron sensitivities $\left(S_{1 \mathrm{n}}-S_{2 \mathrm{n}}\right)$. The photon sensitivities of the detectors investigated were determined at the calibration laboratory at PSI between 24 and $660 \mathrm{keV}$ at normal incidence. The photon sensitivity at $250 \mathrm{keV}$ drops down to $50 \%$ of the sensitivity for ${ }^{137} \mathrm{Cs}$ and for energies $<100 \mathrm{keV}$ to $<5 \%{ }^{(2)}$. Figure 1 shows the ratio of the photon sensitivities in both chambers, $k_{\gamma}$, for the energy region $>60 \mathrm{keV}$ for two detector types. 


\section{CALIBRATION}

The dosemeters were factory calibrated to get the factors $S_{\mathrm{i} \gamma}$ close to unity. An additional calibration of the dosemeters was performed at the calibration laboratory at PSI to determine the factors $S_{\text {in }}$ and to check the factors $S_{\mathrm{i} \gamma}$. The dosemeters were always mounted on the ISO water-slab-phantom. The photon sensitivities were determined by irradiating the dosemeters with a ${ }^{137} \mathrm{Cs}$ source and the neutron sensitivities by irradiation with a ${ }^{241} \mathrm{Am}-\mathrm{Be}$ source. Table 1 summarises the obtained results for the dosemeter types investigated. The photon sensitivities for all dosemeter types agree within $\pm 5 \%$. The neutron sensitivity to ${ }^{241} \mathrm{Am}-\mathrm{Be}$ varies only slightly for different dosemeter types. The dosemeter responses were also determined in a wide range of different neutron fields, covering a large neutron energy range $\mathrm{e}^{(2)}$.

\section{FIELD MEASUREMENTS}

Within the project EVIDOS ${ }^{(3)}$ (Evaluation of Individual Dosimetry in Mixed Neutron and Photon Radiation Fields), which is funded by the EC within

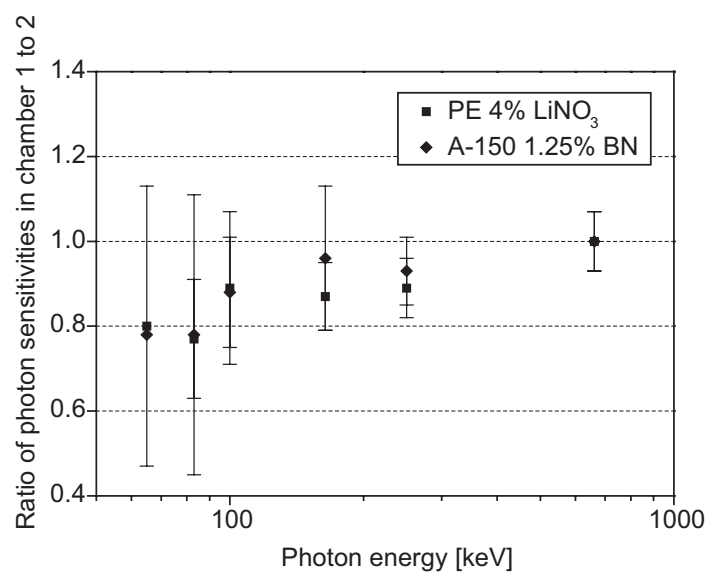

Figure 1. Ratio $k$, of photon sensitivities in the chambers with high-neutron and low-neutron sensitivity for the detector types PE 4\% $\mathrm{LiNO}_{3}$ and A-150 1.25\% BN. the 5 th framework, measurement campaigns at real workplaces in the nuclear industry were performed. Measurements were carried out at a boiling water reactor (KKK SAR and KKK TOP) and at a transport cask with used fuel elements (KKK Cask 1 and KKK Cask 2) at the nuclear power plant in Krümmel, Germany, at a pressurised water reactor (RH A and RH L) and at a transport cask with used fuel elements (RH D and $\mathrm{RH} \mathrm{N}$ ) at the nuclear power plant in Ringhals, Sweden, at the fuel processing plant Belgonucleaire (BELGO), Belgium, and at the research reactor VENUS at CEN•SCK (VENUS), Belgium. Values for the ambient neutron dose equivalent $H^{*}(10)_{\text {BSs }}$ were determined with a bonner sphere spectrometry system ${ }^{(4)}$. With the ratio $H_{\mathrm{p}}(10)_{\mathrm{DS}} / H^{*}(10)_{\mathrm{DS}}$ of personal to ambient neutron dose equivalent, determined with a novel directional spectrometry system $^{(5)}$, a value for the personal neutron dose equivalent $H_{\mathrm{p}}(10)_{\mathrm{DS}}$ can be calculated. For the irradiations, the dosemeters were mounted on a Perspex-slab-phantom of size $30 \times 30 \times 15 \mathrm{~cm}^{3}$. The surface of the slab-phantom, on which the dosemeters $\mathrm{PE} 4 \% \mathrm{LiNO}_{3}$ (bare and with $1 \mathrm{~mm} \mathrm{~B}_{4} \mathrm{C}$ ) were mounted, was oriented to a direction specified to be $0^{\circ}$ (front). The dosemeters A-150 1.25\% BN (bare and with $2 \mathrm{~mm} \mathrm{~B}_{4} \mathrm{C}$ ) were mounted on the opposite surface of the slab-phantom, i.e. surface oriented to the direction $180^{\circ}$ (back). Table 2 shows the measured personal neutron dose equivalent rate $H_{\mathrm{p}}(10)_{\text {DISN }}$, measured with the dosemeter types PE $4 \% \mathrm{LiNO}_{3}$ (bare and with $1 \mathrm{~mm} \mathrm{~B} \mathrm{~B}_{4} \mathrm{C}$ ) and A-150 $1.25 \% \mathrm{BN}$ (bare and with $2 \mathrm{~mm} \mathrm{~B}_{4} \mathrm{C}$ ), respectively, and the values $H^{*}(10)_{\mathrm{BSS}}{ }^{(6)}$ and $H_{\mathrm{p}}(10)_{\mathrm{DS}}{ }^{(7)}$ for all locations and positions. The uncertainties for the values $H^{*}(10)_{\mathrm{BSs}}$ and $H_{\mathrm{p}}(10)_{\mathrm{DS}}$ are in the order of $10 \%$ and up to $30 \%$, respectively.

The locations in the table are sorted using the average conversion factor $h^{*}(10)$ from fluence to ambient dose equivalent, as determined using the Bonner Spheres $^{(6)}$. The typical characteristics of the neutron spectra at the locations RH A, KKK SAR, RH L and KKK Top are a major peak in the thermal region, a broad secondary peak in the intermediate region and almost no fast component $(>1 \mathrm{MeV})$. These spectra are predominated by a thermal contribution.

Table 1. Neutron and photon sensitivities $S_{\text {in }}$ and $S_{\mathrm{i} \gamma}$, in $\mu \mathrm{Sv}$ (a.u.) $)^{-1}$, for the chambers with high $\left(S_{1}\right)$ and low $\left(S_{2}\right)$ neutron sensitivity.

\begin{tabular}{|c|c|c|c|c|}
\hline 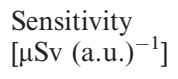 & $\begin{array}{c}\text { PE with } \\
4 \% \mathrm{LiNO}_{3}\end{array}$ & $\begin{array}{c}\mathrm{PE} \text { with } 4 \% \mathrm{LiNO}_{3} \\
\text { and } 1 \mathrm{~mm} \mathrm{~B}_{4} \mathrm{C}\end{array}$ & $\begin{array}{l}\text { A-150 with } \\
1.25 \% \mathrm{BN}\end{array}$ & $\begin{array}{l}\text { A-150 with } 1.25 \% \\
\text { BN and } 2 \mathrm{~mm} \mathrm{~B}_{4} \mathrm{C}\end{array}$ \\
\hline $\mathrm{S}_{1 \gamma} \approx S_{2 \gamma}$ & \multicolumn{4}{|c|}{$1.00 \pm 0.05$} \\
\hline$S_{1 \mathrm{n}}$ & $0.115 \pm 0.006$ & $0.111 \pm 0.006$ & $0.113 \pm 0.006$ & $0.103 \pm 0.006$ \\
\hline$S_{2 \mathrm{n}}$ & $0.048 \pm 0.003$ & $0.046 \pm 0.003$ & $0.048 \pm 0.003$ & $0.045 \pm 0.003$ \\
\hline $\mathrm{S}_{1 n}-\mathrm{S}_{2 n}$ & $0.067 \pm 0.004$ & $0.065 \pm 0.004$ & $0.065 \pm 0.005$ & $0.058 \pm 0.004$ \\
\hline
\end{tabular}


PERFORMANCE OF PERSONAL NEUTRON DOSEMETER DIS-N

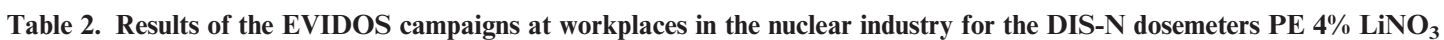
and A-150 1.25\% BN, mounted on the front and back surface of the slab-phantom, respectively (KKK: Krümmel, DE; BELGO: Belgonucleaire, BE; RH: Ringhals, SE; VENUS: SCK•CEN; BE).

\begin{tabular}{|c|c|c|c|c|c|c|c|c|}
\hline \multirow[t]{3}{*}{ Point } & \multirow[t]{3}{*}{$\begin{array}{l}h^{*}(10)^{(6)} \\
\left.(\mathrm{pSv} \mathrm{cm})^{2}\right)\end{array}$} & \multirow{2}{*}{\multicolumn{2}{|c|}{$\begin{array}{c}\begin{array}{c}\text { PE } 4 \% \mathrm{LiNO}_{3} \\
H_{\mathrm{p}}(10)_{\text {DISN }} \\
\left(\mu \mathrm{Sv} \mathrm{h}{ }^{-1}\right)\end{array} \\
\text { Front }\end{array}$}} & \multirow{2}{*}{\multicolumn{2}{|c|}{$\begin{array}{c}\begin{array}{c}\text { A-150 1.25\% BN } \\
H_{\mathrm{p}}(10)_{\text {DISN }} \\
\left(\mu \mathrm{Sv} \mathrm{h}^{-1}\right)\end{array} \\
\text { Back }\end{array}$}} & \multirow[t]{3}{*}{$\begin{array}{c}\mathrm{BSS}^{(6)} \\
H^{*}(10)_{\mathrm{BSS}} \\
\left(\mu \mathrm{Sv} \mathrm{h}^{-1}\right)\end{array}$} & \multicolumn{2}{|c|}{$\begin{array}{c}\mathrm{DS}^{(7)} \\
H_{\mathrm{p}}(10)_{\mathrm{DS}} \\
\left(\mu \mathrm{Sv} \mathrm{h}^{-1}\right)\end{array}$} \\
\hline & & & & & & & Front & Back \\
\hline & & Bare & $1 \mathrm{~mm} \mathrm{~B}{ }_{4} \mathrm{C}$ & Bare & $2 \mathrm{~mm} \mathrm{~B}{ }_{4} \mathrm{C}$ & & & \\
\hline RH A & 30.2 & $1541 \pm 154$ & $620 \pm 62$ & $5321 \pm 532$ & $556 \pm 56$ & 1845 & 614 & 373 \\
\hline KKK SAR & 37.4 & $*$ & * & - & - & 47.6 & 10.6 & \\
\hline RH L & 39.1 & $159 \pm 16$ & $65.3 \pm 7.2$ & $145 \pm 15$ & $32.9 \pm 4.6$ & 253 & 118 & 19.7 \\
\hline KKK Top & 41.1 & $15 \pm 15$ & * & - & - & 40.0 & 23.8 & \\
\hline VENUS F & 48.4 & $116 \pm 23$ & $24.4 \pm 14.9$ & $451 \pm 50$ & - & 153 & 43.8 & 49.4 \\
\hline RH D & 49.6 & $8.6 \pm 3.8$ & $*$ & * & * & 49.0 & 36.0 & 1.6 \\
\hline BELGO 3 & 115 & $23.6 \pm 5.4$ & $13 \pm 6$ & $14.2 \pm 4.8$ & $*$ & 31.9 & 17.3 & 5.4 \\
\hline BELGO 2B & 142 & $27.5 \pm 5.8$ & $13 \pm 6$ & $7.3 \pm 5.5$ & $2.9 \pm 2.9$ & 33.2 & 21.2 & 4.4 \\
\hline KKK Cask 2 & 156 & - & $9.8 \pm 4.9$ & - & - & 55 & 28.4 & \\
\hline KKK Cask 1 & 185 & - & $12 \pm 10$ & - & - & 156 & 109 & \\
\hline BELGO 2A & 260 & $133 \pm 13$ & $117 \pm 13$ & $28.2 \pm 5.1$ & $10.8 \pm 5.5$ & 209 & 162 & 33.6 \\
\hline
\end{tabular}

*, Below detection limit; —, not measured

The neutron spectra at location VENUS $F$ is slightly harder but with similar shape except for the fast component $(>1 \mathrm{MeV})$ which is here up to $5 \%$ of the thermal peak. The spectrum is still predominated by a thermal contribution.

The neutron spectra at locations RH D, KKK Cask 1 and Cask 2 show an important intermediate contribution, a less important fast contribution and only a low peak in the thermal region. These spectra are predominated by an intermediate contribution.

The neutron spectra at locations BELGO 2A, 2B and 3 show important peaks in the thermal region and $>1 \mathrm{MeV}$, nevertheless they are predominated by a fast contribution.

\section{DISCUSSION AND CONCLUSION}

Ideally, the measured values $H_{\mathrm{p}}(10)_{\mathrm{DISN}}$ should agree with the calculated personal dose equivalent $H_{\mathrm{p}}(10)_{\mathrm{DS}}$. This is, however, far away to be the case. The ratio of $H_{\mathrm{p}}(10)_{\mathrm{DISN}}$ to $H_{\mathrm{p}}(10)_{\mathrm{DS}}$ for the bare PE $4 \% \mathrm{LiNO}_{3}$ dosemeter is lowest (0.2) at the location RH D and highest $(\sim 2.5)$ at the locations RH A and VENUS F. At some positions with personal dose equivalent rates below $\sim 100 \mu \mathrm{Sv} \mathrm{h}^{-1}$, the measuring times were too short to get a significant dosemeter signal (KKK SAR and Top). The neutron spectrum at the location RH D has an important peak at $\sim 200 \mathrm{keV}$. In this intermediate neutron energy region, the response of the DIS-N drops to $\sim 0.2$. The neutron spectra at the two locations RH A and VENUS $F$ show a predominant peak in the thermal region. The measured over-response can be explained by the over-response to thermal neutrons by a factor up to 10 for this dosemeter type. At all other locations (RH L, BELGO 1, 2A and 2B) the over response to thermal neutrons compensates more or less the under-response in the intermediate region and the value $H_{\mathrm{p}}(10)_{\text {DISN }}$ agrees within $\pm 30 \%$ with the value $H_{\mathrm{p}}(10)_{\mathrm{DS}}$. The $H_{\mathrm{p}}(10)_{\text {DISN }}$ values for the boron covered $\mathrm{PE} 4 \% \mathrm{LiNO}_{3}$ dosemeter are in all cases lower by a factor of $2-5$ than those for the bare dosemeter. At positions near the transport casks (KKK Cask 1, Cask 2 and RH D), the neutron response of the covered dosemeter drops even more. At these positions, the neutron dose was below or close to the detection limit for the dosemeter type and no useful results could be obtained.

Another very important factor which could prevent a meaningful measurement is the ratio of photon to neutron dose of the mixed neutronphoton field. At all measurement points, except KKK SAR, the ratio of the personal photon to neutron dose equivalent was $<1$. At the measurement point KKK SAR the ratio was $\sim 3$. At the present development status of the dosemeters this ratio is too high and no measurement of a neutron dose is possible.

Most of the considerations above are also true for the results with the A-150 $1.25 \% \mathrm{BN}$ dosemeters. The over-response at the positions with an important thermal neutron peak is important. The addition of a boron cover reduces the values by a factor of 4-10. The shielding effect of the boron cover causes a drop in response and thus an increase in the detection 
Table 3. Detection limits, in $\mu \mathrm{Sv}$, for dosemeter types $\mathrm{PE} 4 \% \mathrm{LiNO}_{3}$ and $\mathrm{A}-1501.25 \% \mathrm{BN}$ for the use in different workplace fields of the nuclear industry and for a ${ }^{241} \mathrm{Am}-\mathrm{Be}$ source assuming a photon to neutron dose ratio of 1.

\begin{tabular}{|c|c|c|c|c|}
\hline \multirow[t]{2}{*}{ Neutron spectra description } & \multicolumn{2}{|c|}{$\begin{array}{l}\mathrm{PE}\left(4 \% \mathrm{LiNO}_{3}\right) \\
H_{\mathrm{p}}(10)_{\mathrm{DISN}}(\mu \mathrm{Sv})\end{array}$} & \multicolumn{2}{|c|}{$\begin{array}{c}\mathrm{A}-150(1.25 \% \mathrm{BN}) \\
H_{\mathrm{p}}(10)_{\mathrm{DISN}}(\mu \mathrm{Sv})\end{array}$} \\
\hline & Bare & $1 \mathrm{~mm} \mathrm{~B}{ }_{4} \mathrm{C}$ & Bare & $2 \mathrm{~mm} \mathrm{~B}_{4} \mathrm{C}$ \\
\hline${ }^{241} \mathrm{Am}-\mathrm{Be}$ source & 100 & 100 & 100 & 100 \\
\hline $\begin{array}{l}\text { Predominant thermal neutron } \\
\text { contribution, i.e. reactor core }\end{array}$ & 50 & 100 & 20 & 200 \\
\hline $\begin{array}{l}\text { Predominant intermediate neutron } \\
\text { contribution i.e. transport/storage cask }\end{array}$ & 500 & $>500$ & 200 & $>500$ \\
\hline $\begin{array}{l}\text { Predominant fast neutron } \\
\text { contribution, i.e. fuel elements }\end{array}$ & 80 & 130 & 80 & 500 \\
\hline
\end{tabular}

limit. The measurements with this dosemeter type become difficult in fields of spectra predominated by an intermediate part.

Table 3 gives the detection limit for different spectra and dosemeter types. The figures were assessed and calculated using formula (3), the uncertainties of the factors $S_{\mathrm{i}}$, the measured values of Table 2, taking for the measured quantities $N_{1}$ and $N_{2}$ an absolute uncertainty \pm 2 a.u. and assuming a photon to neutron dose ratio of 1 . For a dose ratio of 3 the figures in Table 3 would increase by a factor of 2. Even though the relative uncertainty for the measured quantities $N_{i}$ could be very low, a high total dose would result in an increase of the uncertainty of the difference $\left[\left(N_{1}-N_{2}\right) \cdot k_{\gamma}\right]$ and a measurement would become impossible. The results indicate that the investigated dosemeter types are not suited for spectra with an important intermediate peak (near transport casks with used fuel elements). However, in spectra with a predominating thermal peak (near the reactor core of nuclear power plants), the over-response by, at most, a factor of 3 and the detection limit of $<100 \mu \mathrm{Sv}$ make the DIS-N dosemeter a good choice. As expected, in fields of spectra with a fast peak (i.e. almost spectrum of a ${ }^{241} \mathrm{Am}-\mathrm{Be}$ source) the dose measured with the DIS-N dosemeters lies within $\pm 30 \%$ of the expected values.

The $\mathrm{PE} 4 \% \mathrm{LiNO}_{3}$ dosemeter (without or with a boron cover) is suited for the use in neutron spectra predominated by a thermal or fast component. The use of a boron cover reduces the lower detection limits and is thus less recommended. The A-150 $1.25 \% \mathrm{BN}$ is less suited for workplace fields in the nuclear industry. However, in fields with a high thermal neutron component, the uncovered dosemeter may be a good choice. The use of a boron cover with the $\mathrm{A}-1501.25 \% \mathrm{BN}$ dosemeter is not recommended at all for the type of spectra encountered in fields of workplaces in the nuclear industry.

\section{ACKNOWLEDGEMENTS}

This work was partly performed in the framework of EC contract FIKR-CT-2001-00175 and was partly financed by the Federal Office of Education and Science (BBW contract No. 01.0024).

\section{REFERENCES}

1. Fiechtner, A., Wernli, C. and Kahilainen, J. A prototype personal neutron dosemeter based on an ion chamber and direct ion storage. Radiat. Prot. Dosim. 96(1-3), 269-272 (2001).

2. Fiechtner, A., Boschung, M. and Wernli, C. Present status of the personal neutron dosemeter based on direct ion storage. Radiat. Prot. Dosim. 110(1-4), 213-217 (2004).

3. d'Errico, F. et al. Evaluation of Individual Dosimetry in Mixed Neutron and Photon Radiation Fields (EVIDOS). Part I: scope and methods of the project. Radiat. Prot. Dosim. 125(1-4), 263-268 (2006).

4. Lacoste, V., Gressier, V., Pochat, J.-L., Fernández, F., Bakali, M. and Bouassoule, T. Characterisation of Bonner sphere systems at monoenergetic and thermal neutron fields. Radiat. Prot. Dosim. 100(1-4), 529-532 (2004).

5. Luszik-Badra, M., Reginatto, M. and Lacoste, V. Measurement of energy and direction distribution of neutron and photon fluences in workplace fields. Radiat. Prot. Dosim. 100(1-4), 237-241 (2004).

6. Lacoste, V., Assélineau, B., Reginatto, M. and Muller, H. Bonner sphere neutron sspectrometry at nuclear workplaces in the framework of the EVIDOS project. Radiat. Prot. Dosim. 125(1-4), 292-296 (2006).

7. Luszik-Bhadra, M. et al. Directional distributions of neutron and reference values of personal dose equivalent in workplace fields. Radiat. Prot. Dosim. 125(1-4), 352356 (2006). 